\title{
Pythium Species and Isolate Diversity Influence Inhibition by the Biological Control Agent Streptomyces lydicus
}

Jerry E. Weiland, United States Department of Agriculture-Agriculture Research Service, Horticultural Crops Research Laboratory, and Oregon State University, Department of Botany and Plant Pathology, Corvallis 97331

\begin{abstract}
Weiland, J. E. 2014. Pythium species and isolate diversity influence inhibition by the biological control agent Streptomyces lydicus. Plant Dis. 98:653-659.

Disease control of soilborne pathogens by biological control agents (BCAs) is often inconsistent under field conditions. This inconsistency may be partly influenced by pathogen diversity if there is a differential response among pathogen species and isolates to selected BCAs. The responses of 148 Pythium isolates obtained from soil at three forest nurseries and representative of 16 Pythium spp. were evaluated in the presence of Streptomyces lydicus strain WYEC108 in an in vitro assay. Percent growth inhibition, inhibition zone distance, mortality, and growth rate were recorded for each isolate, and data were analyzed for effects of species and isolate. Responses of three Pythium spp. (Pythium irregulare, $P$. sylvaticum, and $P$. ultimum) were further analyzed for a location (nursery) effect. Although $S$. lydicus inhibited all Pythium isolates, differences in percent growth inhibition, inhibition

zone distance, and mortality were observed among Pythium spp. and isolates. Small but significant location effects were also noted. Growth rate also varied among Pythium spp. and isolates and was found to strongly bias percent growth inhibition and, to a lesser degree, inhibition zone distance; depending on which measure was used, slowergrowing isolates appeared less sensitive (growth inhibition) or more sensitive (inhibition zone) to $S$. lydicus than faster-growing isolates. Results illustrate the importance of using multiple, representative pathogen isolates in preliminary BCA inhibition assays as well as accounting for the effect of pathogen growth rate on pathogen inhibition by BCAs. Future studies should take pathogen diversity into account when evaluating biological control efficacy.
\end{abstract}

Pythium spp. cause damping-off and root rot in forest seedling nurseries worldwide and are considered one of the most important soilborne pathogens affecting tree seedling production $(41,44-46)$. In the Pacific Northwest (PNW) region of the United States (Idaho, Oregon, and Washington), forest nurseries rely on periodic fumigation with either methyl bromide or dazomet for control of Pythium spp. and other soilborne pathogens $(43,45,46)$. Chemical fumigants have long been preferred for soilborne disease control in forest nurseries because of their broad-spectrum, nonselective activity against numerous soilborne plant-pathogenic genera, and for their additional activity against soilborne insect pests and weed species. Nursery managers may also apply specific fungicides such as mefenoxam during the growing season for supplemental disease control. As state and federal regulatory agencies place greater restrictions on the use of fumigants for tree seedling production, alternative measures of disease control are increasingly desired by the forest nursery industry. Ideally, these disease control measures would have minimal environmental impact and pose little to no risk for human health.

Forest nursery managers have been interested in using biological control agents (BCAs) against soilborne pathogens because biological control is considered more environmentally sustainable and less toxic than conventional chemical fumigants and pesticides $(2,9)$. Unfortunately, there have been few successes in the use of BCAs in forest tree seedling production $(7,8,17,21,25,28,36)$, and many growers cite inconsistent results or a lack of disease control as the primary reason for not using biological control in their nursery (interviews with 14 forest nursery managers by the author in 2011, personal communication). In general, BCAs do not have the same degree of broad-spectrum activity against the wide vari-

Corresponding author: J. Weiland, E-mail: Jerry.Weiland@ ars.usda.gov

Accepted for publication 2 December 2013.

http://dx.doi.org/10.1094/PDIS-05-13-0482-RE

(C) 2014 The American Phytopathological Society ety of soilborne pathogens that has been exhibited by chemical fumigants. Although biocontrol is sometimes thought to be more effective under conditions with relatively low biodiversity (12), including low pathogen diversity (37), many individual BCAs are labeled as having relatively broad-spectrum activity against multiple soilborne phytopathogenic genera or species. As a result, researchers and growers have frequently applied single BCA strains in attempts to control soilborne diseases that are caused by multiple phytopathogenic agents such as damping-off or root rot $(10,19,21,27,31,35)$. In some cases, subsequent disease control was successful $(10,19,31,35)$ whereas, in others, it was not $(21,27,35)$.

Most of the research regarding biocontrol efficacy has focused primarily on factors associated with the BCA or its interaction with the rhizosphere and edaphic environment. These factors include the BCA application dose and resultant population size, rhizosphere competence, survival, effects of BCA genetic diversity on disease control, mechanisms of pathogen suppression (e.g., antibiotics, competition, and so on), substrate interactions (e.g., soil versus compost), and BCA nutritional requirements $(6,18,37,47)$. In comparison, very little research has been conducted to quantitatively determine how much variability within pathogen communities (among species) or populations (among isolates of the same species) contributes to the outcome of biological control $(32,37)$. Research that specifically and systematically evaluates the responses of representative isolates from local, naturally occurring pathogen communities or populations to selected BCAs is also lacking (32). Although there are many BCA studies that assess several pathogen species or isolates, the number of species or isolates evaluated is usually extremely limited and, as a consequence, there is limited statistical inference about the contribution of pathogen species or isolate diversity to BCA inhibition $(5,6,11,28,35-37,48,50)$. Furthermore, the pathogen taxa used in many biological control assays are often not representative of the greater genotypic and phenotypic diversity existing in the field. In many cases, the pathogen isolates were collected from different geographic locations, plant hosts, or culture collections $(9,11,22,26,29,32,35,37,38,42,48,50)$. Knowledge about the degree to which BCA inhibition is influenced by pathogen species and isolate diversity is particularly relevant to 
the forest nursery industry, where multiple Pythium spp., each consisting of numerous isolates, are found within a single nursery field $(16,43,46)$. These factors may help explain why biological control success has been elusive in forest nursery settings.

Streptomyces spp. have been used as BCAs against a number of soilborne pathogens, including phytopathogenic Pythium spp. $(3,4,8,9,23,24,29,35,37,48,50)$. Actinovate is a commercially available formulation of Streptomyces lydicus strain WYEC108 that is labeled for use in nurseries. The strain has both chitinolytic and antibiotic properties that are effective against Pythium spp. $(3,30,50)$. An initial study in 1995 indicated that this strain suppressed damping-off of pea by Pythium ultimum (50), which is also a widespread pathogen in forest nurseries of the PNW (43). However, the commercial product was ineffective in reducing dampingoff of greenhouse-grown Douglas-fir seedlings inoculated with a single isolate of $P$. irregulare (28). Its failure to provide control in the latter case was attributed to improper application timing in relation to the extent of pathogen activity (the BCA was applied after seeding into infested soil) and not to the potential inability of the strain to inhibit that particular Pythium sp. or isolate. Although S. lydicus strain WYEC108 does have broad-spectrum activity against multiple plant pathogens (50), it is unknown whether the BCA is capable of inhibiting the Pythium spp. found in PNW forest nursery fields or whether it inhibits all Pythium spp. and isolates equally.

The culture collection of Pythium isolates obtained during a previous survey of Pythium spp. diversity in three PNW forest nurseries provided the opportunity to examine whether multiple Pythium spp. and isolates, which were representative of three different locally and naturally occurring pathogen communities, were inhibited to different degrees by the presence of the BCA, S. lydicus. The objectives of this study were to investigate whether $S$. lydicus could inhibit the Pythium spp. and isolates important to the forest nursery industry and to quantify whether pathogen diversity (at the species, isolate, and nursery or location level) affected in vitro inhibition by $S$. lydicus prior to the application of this BCA to more expensive and time-consuming field trials, where multiple Pythium spp. and isolates would be present. Specifically, three null hypotheses were tested: (i) Pythium spp. do not differ in response to $S$. lydicus (community level), (ii) Pythium isolates of the same species do not differ in response to S. lydicus (population level), and (iii) Pythium isolates of the same species but obtained from different locations (nurseries) do not differ in response to $S$. lydicus (locational level). In order to limit the number of potentially confounding environmental variables which might obscure the relative impact of species, isolate, and location on inhibition of Pythium by $S$. lydicus, an in vitro approach was used to compare the responses of each Pythium isolate (growth rate, percent growth inhibition, inhibition zone distance, and mortality) to the presence of $S$. lydicus in a dual-culture assay.

\section{Materials and Methods}

Isolate selection. In all, 148 Pythium isolates were selected from the isolate collection of a previous soil survey at three forest nurseries in Washington and Oregon (43; Table 1). In that study, 100 isolates were originally selected at random from each of the three nurseries (nursery A in southwestern Washington and nurseries $\mathrm{B}$ and $\mathrm{C}$ in northwestern Oregon) and from each of three isolation methods used at each nursery (dilution plating and baiting with rhododendron leaf disks or Douglas-fir needle segments) to yield 900 total isolates (300 isolates from each nursery). Each isolate was then identified to species by comparing the sequence of the internal transcribed spacer (ITS) region to the ITS sequences of ex-type cultures or authentic strains, then confirming species identity via morphology (43). Isolates were subsequently selected for this study as representatives of 16 of the 19 species found at the three nurseries. In a prior inoculation study, isolates of $P$. dissotocum, $P$. irregulare, $P$. aff. macrosporum, $P$. mamillatum, $P$. aff. oopapillum, $P$. rostratifingens, $P$. sylvaticum, and $P$. ultimum were characterized as highly virulent (or aggressive) pathogens, with the remaining eight species characterized as weakly virulent pathogens (44). Whenever possible, isolates that were representative of a particular species were also chosen to originate from each of the three nurseries in order to encompass potential geographic variability. Particular emphasis was placed on obtaining at least 30 isolates of three highly virulent Pythium spp. (P. irregulare, $P$. sylvaticum, and $P$. ultimum) in order to assess the potential for location-tolocation variability among isolates. These three species were also chosen based on their association with damping-off disease of conifers in previous studies $(20,41,44,45)$, and their presence in comparatively large numbers at more than one nursery during the 2008 survey (43). P. irregulare was obtained from all three nurse-

Table 1. Mean values of growth rate, percent growth inhibition at day 2 and 7, inhibition zone distance, and mortality of Pythium spp. grown in dual-culture assays with Streptomyces lydicus strain WYEC108

\begin{tabular}{|c|c|c|c|c|c|c|}
\hline Species & $N^{\mathbf{z}}$ & $\begin{array}{l}\text { Growth rate } \\
(\mathrm{mm} / \mathrm{day})\end{array}$ & $\begin{array}{l}\text { Percent growth } \\
\text { inhibition day } 2\end{array}$ & $\begin{array}{l}\text { Percent growth } \\
\text { inhibition day } 7\end{array}$ & $\begin{array}{l}\text { Inhibition zone } \\
\text { distance }(\mathbf{m m})\end{array}$ & $\begin{array}{l}\text { Percent } \\
\text { mortality }\end{array}$ \\
\hline Pythium aff. mercuriale & 1 & $9 \pm 0.3(-) \mathrm{a}$ & $35 \pm 0.0(-) \mathrm{abc}$ & $62 \pm 0.0(-) \mathrm{cde}$ & $37 \pm 0.0(-) \mathrm{a}$ & $100 \pm 0.0 \mathrm{ab}$ \\
\hline P. torulosum & 4 & $10 \pm 0.1(9-11) \mathrm{a}$ & $20 \pm 2.0(16-25) \mathrm{f}$ & $60 \pm 0.9(58-61) \mathrm{f}$ & $34 \pm 0.6(32-35) \mathrm{a}$ & $75 \pm 0.7 \mathrm{bc}$ \\
\hline P. middletonii & 2 & $11 \pm 0.5(11-12) \mathrm{a}$ & $23 \pm 3.6(19-27)$ ef & $61 \pm 1.9(59-63)$ def & $29 \pm 2.6(26-31) b$ & $100 \pm 0.0 \mathrm{a}$ \\
\hline$P$. rostratifingens & 2 & $18 \pm 2.2(9-28) b$ & $29 \pm 9.6(19-38) \mathrm{de}$ & $61 \pm 4.2(57-65)$ ef & $28 \pm 5.5(23-34) b$ & $50 \pm 11.5 \mathrm{c}$ \\
\hline P. dissotocum & 2 & $21 \pm 1.1(16-26) c$ & $34 \pm 7.0(27-41) a b c$ & $64 \pm 2.2(62-66) a b c$ & $25 \pm 0.7(24-25) c$ & $100 \pm 0.0 \mathrm{a}$ \\
\hline P. irregulare & 54 & $25 \pm 0.1(20-28) \mathrm{d}$ & $37 \pm 0.6(20-43) a$ & $65 \pm 0.2(60-67) \mathrm{a}$ & $24 \pm 0.3(18-27) \mathrm{c}$ & $96 \pm 0.8 \mathrm{a}$ \\
\hline P. aff. spiculum & 2 & $25 \pm 1.1(25-26) \mathrm{d}$ & $36 \pm 2.3(34-39) \mathrm{ab}$ & $64 \pm 1.0(63-65) a b$ & $24 \pm 0.5(23-24) \mathrm{cd}$ & $100 \pm 0.0 \mathrm{a}$ \\
\hline P. pachycaule & 2 & $17 \pm 0.4(16-19) b$ & $25 \pm 2.6(22-27)$ ef & $61 \pm 0.6(60-61)$ ef & $23 \pm 3.1(20-26)$ cde & $100 \pm 0.0 \mathrm{a}$ \\
\hline P. 'vipa' & 2 & $26 \pm 0.3(25-27) \mathrm{de}$ & $37 \pm 1.0(36-38) \mathrm{a}$ & $65 \pm 0.6(64-65) \mathrm{a}$ & $22 \pm 0.6(21-22)$ cdef & $100 \pm 0.0 \mathrm{a}$ \\
\hline P. mamillatum & 2 & $23 \pm 0.7(20-25) c$ & $30 \pm 2.5(27-32) \mathrm{cd}$ & $63 \pm 0.6(62-63)$ cde & $21 \pm 0.9(20-22)$ cdef & $100 \pm 0.0 \mathrm{a}$ \\
\hline P. irregulare group IV & 2 & $29 \pm 0.4(29-30) \mathrm{f}$ & $36 \pm 1.1(35-37) a b$ & $64 \pm 0.4(64-65) a b$ & $20 \pm 0.1(20-20)$ defg & $100 \pm 0.0 \mathrm{a}$ \\
\hline P. sylvaticum & 36 & $31 \pm 0.2(19-35) \mathrm{f}$ & $36 \pm 0.7(30-44) \mathrm{a}$ & $65 \pm 0.3(62-68) a$ & $20 \pm 0.6(14-26)$ ef & $99 \pm 0.5 \mathrm{a}$ \\
\hline P. irregulare group III & 1 & $29 \pm 0.6(-)$ ef & $33 \pm 0.0(-)$ abcd & $63 \pm 0.0(-)$ abcd & $19 \pm 0.0(-)$ efg & $100 \pm 0.0 \mathrm{ab}$ \\
\hline P. aff. macrosporum & 3 & $30 \pm 0.4(30-30) \mathrm{f}$ & $36 \pm 1.1(34-38) a b$ & $64 \pm 0.4(64-65) a b$ & $19 \pm 1.0(18-21) \mathrm{fg}$ & $100 \pm 0.0 \mathrm{a}$ \\
\hline P. aff. oopapillum & 1 & $18 \pm 0.3(-) b$ & $20 \pm 0.0(-) \mathrm{f}$ & $59 \pm 0.0(-) \mathrm{f}$ & $19 \pm 0.0(-)$ efg & $100 \pm 0.0 \mathrm{ab}$ \\
\hline P. ultimum & 32 & $27 \pm 0.2(20-32) \mathrm{e}$ & $33 \pm 0.6(24-39) b c$ & $63 \pm 0.2(60-66) b c$ & $18 \pm 0.4(13-23) \mathrm{g}$ & $98 \pm 0.7 \mathrm{a}$ \\
\hline
\end{tabular}

y A 2-mm-diameter culture of $S$. lydicus was placed $1 \mathrm{~cm}$ from the edge of a plate containing potato dextrose agar (PDA) 2 days before a 5-mm-diameter plug of each Pythium isolate was placed on the opposite side of the plate. Negative control plates did not have a culture of $S$. lydicus. Percent growth inhibition ( 1 - Pythium culture radius in the presence of S. lydicus/Pythium culture radius in the absence of S. lydicus) was evaluated at 2 and 7 days. Inhibition zone distance (the minimum distance at which Pythium isolate growth toward the S. lydicus culture stopped) and percent mortality (evaluated by subculturing from the culture margin of the Pythium isolate on the dual culture plate onto fresh PDA) were evaluated at 7 days. Values represent species means (pooled data set from both trials as adjusted for growth rate) \pm standard error, with the range among isolate means $(n=10)$ in parentheses. Values with the same letter within the same column are not significantly different at $P=0.05$ according to Tukey's procedure or by individual contrasts among each pair of treatments (for mortality data only).

${ }^{\mathrm{z}}$ Number of isolates. 
ries (nursery $\mathrm{A}=23$ isolates, nursery $\mathrm{B}=19$ isolates, and nursery $\mathrm{C}=12$ isolates). However, $P$. ultimum and $P$. sylvaticum were rarely or never isolated from nursery A. Therefore, isolates for these species were only obtained from nurseries B $(P$. sylvaticum $=$ 17 isolates and P. ultimum $=12$ isolates $)$ and $\mathrm{C}(P$. sylvaticum $=19$ isolates and $P$. ultimum $=20$ isolates). All isolates were stored on colonized water agar plugs in sterile distilled water at $20^{\circ} \mathrm{C}$ when not in use, and as active cultures on plates containing $20 \mathrm{ml}$ of potato dextrose agar (PDA).

In vitro assay. Each of the 148 Pythium isolates were tested alone or in combination with $S$. lydicus strain WYEC108 (Actinovate SP, Natural Industries, Inc.) and assessed for Pythium culture radial growth and mortality. Procedures were modified from a similar assay used to assess the activity of strain WYEC108 against several plant pathogens and in which results were indicative of subsequent damping-off control by the BCA in pea inoculated with P. ultimum (50). Cultures of $S$. lydicus ( $2 \mathrm{~mm}$ in diameter) were initiated on plates containing $15 \mathrm{ml}$ of PDA, $1 \mathrm{~cm}$ from the plate edge, and then incubated at $20^{\circ} \mathrm{C}$ for 2 days. A 5-mm-diameter Pythium-colonized agar plug was then placed on the opposite side of the plate, also $1 \mathrm{~cm}$ from the plate edge, for each of the Pythium isolates. Negative control plates containing only a single culture of S. lydicus or one of the Pythium isolates were also prepared. Plates were then incubated at room temperature, with daily measurements of culture radii for S. lydicus and each Pythium isolate for 7 days. The radius of S. lydicus and each Pythium isolate was measured to the nearest millimeter in the direction toward the opposite side of the plate where the opposing culture was located. Cultures of $S$. lydicus remained the same size throughout the duration of the experiment and these data were not evaluated further. In addition, the distance in millimeters between the $S$. lydicus culture and each Pythium isolate was measured daily. After 7 days, a 5-mm-diameter agar plug was taken from the culture margin of each Pythium isolate from the side that was closest to the $S$. lydicus culture and then transferred to a new plate of PDA to evaluate Pythium isolate mortality. Each Pythium isolate-S. lydicus treatment, as well as each negative control treatment, was replicated five times and the entire experiment was conducted twice. Plates were arranged according to a complete randomized design.

Data analyses. Growth rate (millimeters per day) for each isolate was calculated as the average increase in the culture radius over 3 days on negative control plates. The ability of S. lydicus to inhibit Pythium spp. growth at 2 and 7 days was expressed as a percentage [ $(1-$ Pythium culture radius in the presence of $S$. lydicus/Pythium culture radius in the absence of $S$. lydicus $) \times 100$ for each of the Pythium isolates (percent growth inhibition)]. Because percent growth inhibition was found to be strongly biased based on growth rate data, a second, less-biased measure of the ability of $S$. lydicus to inhibit Pythium growth was defined as the minimum distance at which the growth of the Pythium isolate toward the $S$. lydicus culture stopped and no further growth by the Pythium isolate toward the $S$. lydicus culture was observed for at least $24 \mathrm{~h}$ (inhibition zone distance). This distance was reached for all Pythium isolates in the study by day 7. Pythium mortality was rated for each replicate plate as either 0 (dead) or 1 (living).

Growth rate data were analyzed using analysis of variance (ANOVA), with species as a fixed factor and trial and isolate (nested within species) as random factors. Growth inhibition data (at 2 and 7 days) were converted into proportions and transformed with the arcsine of the square root to correct for heteroscedasticity. Inhibition zone data met assumptions for normality and equal variance and, therefore, were not transformed. In preliminary analyses, growth rate was observed to affect both growth inhibition and inhibition zone data. Therefore, both dependent variables were assessed using the same ANOVA model as described above but with growth rate as a covariate. For isolates of $P$. irregulare, $P$. sylvaticum, and $P$. ultimum, growth inhibition and inhibition zone data were further evaluated for locational effects by adding nursery as a fixed factor. Treatment means were separated using Tukey's procedure (39). In order to evaluate the relative contribution of species, isolate, and locational variation toward the total variation of the ANOVA model, effect sizes ( $\eta^{2}$ values) were calculated, where $\eta^{2}$ is defined as the proportion of total variation that is attributed to a particular factor and ranges from 0 to 1 (39). Mortality frequency data were analyzed via Fisher's exact test, an approach similar to $\chi^{2}$ analyses but used when some contingency table cell counts are too small (39). Mortality treatment means were separated by conducting individual contrasts among each pair of treatments. All analyses were performed with Minitab Statistical Software (release 15; Minitab Inc.) and SAS 9.2 (SAS Institute Inc.).

\section{Results}

Growth rate varied among Pythium spp. $(P<0.001)$, with $P$. aff. mercuriale growing the slowest at $9 \mathrm{~mm} /$ day and $P$. sylvaticum growing the fastest at $31 \mathrm{~mm} /$ day (Table 1). Differences were also observed among isolates within each species $(P<0.001)$ but there was much more variation in growth rate among species $\left(\eta^{2}=0.65\right)$ than among isolates within species $\left(\eta^{2}=0.20\right)$. There was no effect of trial $(P=0.236)$. Growth rate was observed to affect both growth inhibition (at days 2 and 7) and inhibition zone distance $(P$ $<0.001)$. However, a much greater proportion of the total variation was attributed to growth rate in the growth inhibition analyses $\left(\eta^{2}\right.$ $=0.51$ for day 2 and $\eta^{2}=0.56$ for day 7) than in the inhibition zone analyses $\left(\eta^{2}=0.11\right)$, indicating that growth rate had a much larger effect on growth inhibition than inhibition zone distance.

Pythium spp. varied greatly in their response to $S$. lydicus at day $2(P<0.001)$, with $P$. irregulare and $P$. 'vipa' exhibiting the most growth inhibition (37\%), and P. torulosum and P. aff. oopapillum experiencing the least (20\%) (Table 1). Growth inhibition also varied greatly among isolates within each species $(P<0.001)$. Isolates of $P$. irregulare, for example, had the greatest range in growth inhibition, with one isolate that was weakly inhibited (20\%) compared with all other isolates, which were more strongly inhibited (31 to $43 \%$ ). Conversely, P. torulosum isolates were all relatively weakly inhibited (16 to $25 \%$ ). As a result, the variation observed among isolates within species $\left(\eta^{2}=0.17\right)$ was greater than that observed among species $\left(\eta^{2}=0.08\right)$. Although a trial effect was observed $(P<0.001)$, results were consistent within each trial separately (data not shown) and the size of the effect was small $\left(\eta^{2}=0.02\right)$.

By day 7, growth inhibition had increased for all Pythium spp. and the range between the most- and least-inhibited species had narrowed from 17 percentage points (at 2 days) to 6 percentage points: P. irregulare, $P$. sylvaticum, and $P$. 'vipa' exhibited the most growth inhibition (65\%) and P. aff. oopapillum the least $(59 \%)$ (Table 1). As a result, there was some decrease in the ability to distinguish between species but significant differences were still evident $(P<0.001)$ and species were ranked similarly from most to least inhibited, as was observed at day 2 . Growth inhibition was also greater among all Pythium isolates within each species, with every isolate exhibiting at least $57 \%$ inhibition. However, growth inhibition at day 7 still varied significantly among isolates within species $(P<0.001)$. As was found at day 2 , the variation observed among isolates within the same species $\left(\eta^{2}=0.16\right)$ was greater than that observed among species $\left(\eta^{2}=0.07\right)$. A trial effect was observed $(P<0.001)$ but results were consistent within each trial separately (data not shown) and the size of the effect was small $\left(\eta^{2}\right.$ $=0.01$ ).

The inhibition zone distance between $S$. lydicus and each Pythium isolate varied among Pythium spp. $(P<0.001)$ and ranged from $37 \mathrm{~mm}$ for $P$. aff. mercuriale to $18 \mathrm{~mm}$ for $P$. ultimum (Table 1). However, the ranking of each species with inhibition zone data from most to least inhibited was different than that observed for the growth inhibition data. For example, $P$. 'vipa', which was one of the species most inhibited by $S$. lydicus according to the growth inhibition data, was only the ninth most-inhibited species based on inhibition zone data. P. torulosum, on the other hand, was one of the least inhibited Pythium spp. according to the growth inhibition data but was the second most-inhibited species when inhibition zone data were used. As observed for the percent growth inhibition 
data, inhibition zone distance also varied among isolates within each species $(P<0.001)$ but the variation among isolates within species $\left(\eta^{2}=0.23\right)$ was about the same as that observed among species $\left(\eta^{2}=0.24\right)$. Although a trial effect was observed $(P<$ 0.001 ), results were consistent within each trial separately (data not shown $)$ and the size of this effect was small $\left(\eta^{2}=0.07\right)$.

For isolates of $P$. irregulare, $P$. sylvaticum, and $P$. ultimum, there was a small but significant effect of location $(P<0.001)$ on the inhibition zone distance (Fig. 1). For example, the average length of the inhibition zone for $P$. sylvaticum isolates was less at nursery B $(19 \mathrm{~mm}, n=17)$ than at nursery C $(23 \mathrm{~mm}, n=19)$. Similar location effects were also observed for growth inhibition data at day 2 and 7 (data not shown). The variation due to location was least among $P$. ultimum $\left(\eta^{2}=0.05\right)$ and $P$. irregulare $\left(\eta^{2}=0.07\right)$ isolates and greatest for $P$. sylvaticum isolates $\left(\eta^{2}=0.14\right)$.

Most Pythium isolates, regardless of species, were killed after exposure for 7 days to $S$. lydicus (Table 1). However, 10 isolates were observed to survive exposure 10 to $60 \%$ of the time (6 isolates of $P$. irregulare and 2 isolates each of $P$. sylvaticum and $P$. ultimum). Three Pythium isolates were never killed (one isolate each of $P$. irregulare, $P$. rostratifingens, and $P$. torulosum). As a result, differences in mortality were observed among Pythium spp. $(P \leq 0.023)$. No trial effect was observed $(P=0.126)$.

\section{Discussion}

To my knowledge, this study is the first to utilize a relatively large number of pathogen species and isolates, which are also representative of locally and naturally occurring soilborne pathogen communities, to quantitatively assess the importance of pathogen species, isolate, and locational diversity to the variability of BCA inhibition. Most BCA assays have evaluated only a limited number of pathogen species or isolates $(1,3,11,26,34,40,42,50)$, which could result in an incomplete assessment of the variability in biocontrol inhibition prior to the deployment of the BCA into sites with greater pathogen diversity. Previous studies were further limited in that the tested pathogen species and isolates were often obtained from disparate plant hosts $(4,5,29,32,38,50)$, research collections $(5,23,26,32,38,48,50)$, or geographic regions $(4,5,9$, $26,29,32,37,38,50)$ and, therefore, were not necessarily repre-

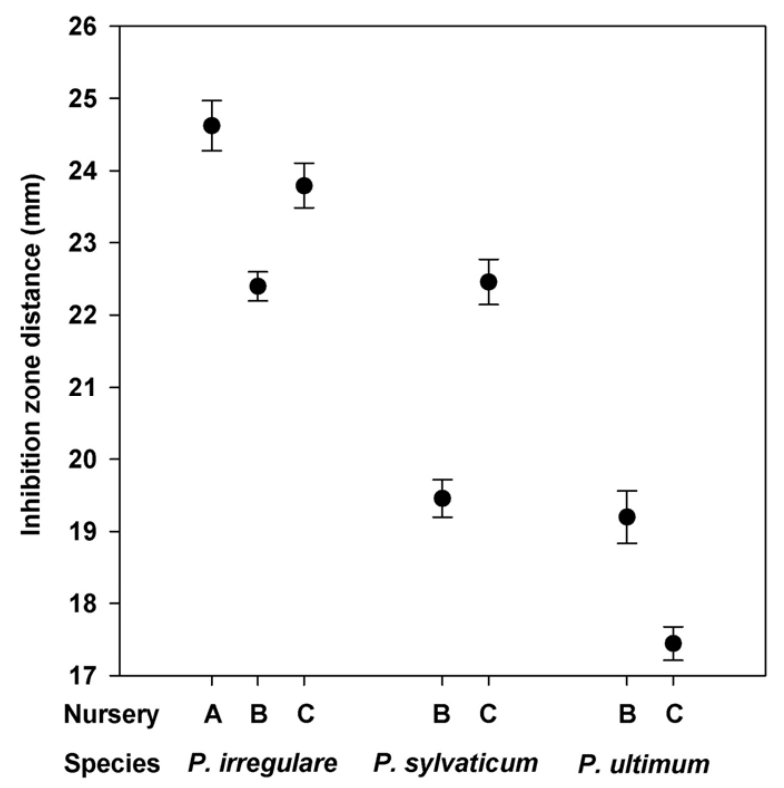

Fig. 1. Differences in mean inhibition zone distance among isolates of three Pythium spp. isolated from soil at two or three forest nurseries. Means were calculated from the pooled data set from both trials as adjusted for growth rate. Each Pythium isolate was grown in dual culture with Streptomyces lydicus strain WYEC108 on potato dextrose agar. Inhibition zone distance was defined as the minimum distance at which the growth of the Pythium isolate toward the $S$. Iydicus culture stopped and no further growth was observed (7 days). Bars represent the standard error of the mean ( $n=12$ to 23 isolates, 10 replicates each). sentative of the pathogen populations or communities to which the BCA would eventually be applied. Although others have found differences in biocontrol inhibition among different pathogen species, isolates, and locations, there has been little statistical support for these observations $(4,5,9,14,22,26,32,35,37,38$, $42,48,50)$. The use of a small number of potentially nonrepresentative tester isolates likely constrains the range of BCA inhibition responses that are observed and could partly explain why the success reported in many early BCA assays $(3,36,50)$ has not been a good indicator of the BCA's performance when targeted toward a more diverse array of pathogen species and isolates $(21,27,28)$. For example, although $S$. lydicus strain WYEC108 was effective against four isolates of $P$. ultimum in early in vitro, growth chamber, and greenhouse assays $(3,50)$, it was not effective in controlling damping-off of chickpea in a greenhouse assay with a different $P$. ultimum isolate or in a field assay with an unquantified number of $P$. ultimum isolates (27). The large number of representative Pythium spp. and isolates used in the present study, particularly those of $P$. irregulare, $P$. sylvaticum, and $P$. ultimum, allowed for meaningful, quantitative analyses to be made regarding the variability of inhibition responses among species, isolates, and locations before implementing more expensive and time-consuming field trials. Results indicate that BCA inhibition can be significantly influenced by pathogen diversity at three distinct levels (species, isolate, and location) and show that the greatest variation in the inhibitory response, as measured by inhibition zone distance and adjusted for growth rate, occurred among species $\left(\eta^{2}=0.23\right)$ and isolates $\left(\eta^{2}=0.24\right)$, with the least variation among isolates from different locations $\left(\eta^{2}=0.05\right.$ to 0.14$)$. Therefore, all three null hypotheses of this study were rejected.

Although the differences in the inhibition zone distance observed between species, isolate, and location are small (millimeter range), this is not unexpected for soilborne microorganisms which are themselves approximately 1,000-fold smaller in size (micrometer range). Although there is little information about how far the chitinolytic enzymes and antibiotics produced by rhizospherecolonizing microbes (such as S. lydicus) can diffuse from their point of origin, it is unlikely that biologically active concentrations extend much more than a few millimeters from the colonized root surface. Thus far, BCA-produced antibiotics have been detected primarily from the rhizosphere and not in bulk soil, where the antibiotics are thought to be reduced to subactive levels through microbial degradation and by adsorption to organic matter or clay particles (15).

To date, only a limited number of Pythium spp. have been evaluated for inhibition by $S$. lydicus $(13,27,28,30,33,50)$. Most published studies tested $S$. lydicus only against $P$. ultimum $(13,27,30,50)$. However, Linderman et al. (28) tried S. lydicus against $P$. irregulare and found that the BCA was ineffective in reducing damping-off of Douglas-fir seedlings in a greenhouse assay involving this pathogen. In the present study, 148 isolates representing 16 Pythium spp. and three Pythium communities were assessed. Therefore, this study is the first to report the sensitivity of 14 Pythium spp. to S. lydicus strain WYEC108: P. dissotocum, $P$. irregulare group III, $P$. irregulare group IV, $P$. aff. macrosporum, P. mamillatum, $P$. aff. mercuriale, $P$. middletonii, $P$. aff. oopapillum, $P$. pachycaule, $P$. rostratifingens, $P$. aff. spiculum, $P$. sylvaticum, $P$. torulosum, and $P$. 'vipa'. This study also serves as the most comprehensive assessment to date of the interactions between a BCA and the Pythium spp. that are important to the PNW forest nursery industry.

The effect of pathogen diversity on biocontrol efficacy is of fundamental importance during the registration process of a BCA as a biopesticide. One reason for the frequent failure of biological control in the field may lie with the assumption that BCAs will perform in a manner similar to synthetic chemical pesticides with broad-spectrum activity. Pesticide labels for BCAs often indicate activity against multiple phytopathogenic genera but it is not readily apparent how robust the underlying assays were in terms of the numbers of species and isolates tested without extensive backtrack- 
ing through the scientific literature or the product registration records through the Environmental Protection Agency. Much of this information may also be proprietary and, therefore, unavailable for reference. It is also important to note that an indication of activity against specific pathogenic genera does not relay information about whether the BCA is equally effective against all species within a particular genus to the same degree. Greater transparency and ease of access to information regarding the species diversity and isolate numbers tested in initial biocontrol assays would assist both scientists and growers in determining whether a specific BCA is appropriate for a particular application involving soilborne diseases with multiple causal agents or whether additional information is needed before an application is attempted.

Successful and consistent biological control of soilborne plant diseases has been challenging to achieve in the field. Numerous biotic and abiotic factors influence biological control success, and any genotypic or phenotypic variability inherent in the host plant, pathogen, or BCA population will also affect the outcome. However, many agricultural systems limit host plant diversity through monoculture. BCAs, which are often applied as a single strain or as a mixture of several species or strains $(7,8,14,21,28,50)$, are similarly limited in diversity. The diversity of pathogen communities and populations, in contrast, is not directly controlled and may be quite variable $(6,32,37)$. The three forest nursery fields from which the Pythium isolates in this study were obtained, for example, were cropped with Douglas-fir for at least three consecutive years following fumigation, yet numerous isolates of 19 Pythium spp. were identified from field soil samples (43). Similar circumstances are found in many other agricultural systems, which brings into question whether any one particular biological control treatment can effectively inhibit all pathogen species and isolates equally. Given the results of this study, as well as the diversity of Pythium spp. and isolates present at each forest nursery, it seems unlikely that any single BCA could effectively control Pythium damping-off in forest nurseries. Recent applications of S. lydicus strain WYEC108 to field-grown Douglas-fir seedlings in soils with $P$. irregulare, $P$. sylvaticum, and $P$. ultimum thus far have proven ineffective for disease control despite the successful reisolation of the BCA from tree seedling roots, which indicates that the BCA survived and colonized the root system (unpublished data). Although there are many possible explanations for the lack of disease control by the BCA in the field, it seems reasonable to suspect that at least some component of this failure can be attributed to the significant differences in sensitivity to $S$. lydicus among these three Pythium spp. and to the presence of an almost twofold difference in inhibition between the most- and least-sensitive isolates within each species. One strategy that might improve field biocontrol would be the combined use of multiple BCAs, each with complementary, synergistic activity against multiple pathogen species $(14,37,49)$. However, results from combined BCA studies have been mixed, and component BCAs are often antagonistic to each other, resulting in no better disease control than from the single, most efficacious BCA applied alone (49). Another strategy that may hold promise is the combination of BCAs with fungicide treatments or other soilborne disease control measures such as bare fallow, irrigation management, or organic amendments (46). However, results combining BCAs with fungicides have been mixed $(10,27,28)$ and, until methods are developed that allow BCAs to perform consistently in the field, biocontrol is unlikely to become a major strategy for controlling soilborne pathogens in forest nurseries.

One unintended consequence of utilizing the in vitro approach was that percent growth inhibition was identified as a more biased measure of BCA inhibition than inhibition zone distance. Although growth inhibition is a common method of evaluating inhibition in many in vitro assays $(1,2,9,24,32,34,40)$, this dependent variable was greatly influenced by differences in growth rate among Pythium isolates $\left(\eta^{2}=0.51\right.$ to 0.56$)$ compared to inhibition zone distance $\left(\eta^{2}=0.11\right)$. Growth inhibition data were originally recorded daily to determine the optimal length of time that the in vitro assay needed to run to detect differences among Pythium spp. and isolates. The effect of growth rate on percent growth inhibition only became apparent once day 2 data were compared with day 7 data and the differences in magnitude and range between the minimum and maximum inhibition values were noted. Because of their growth rate, faster-growing species and isolates will exhibit greater percent growth inhibition and smaller inhibition zone distances than their slower-growing counterparts with the same sensitivity to the BCA. For example, if two Pythium isolates were hypothetically inhibited to the same degree by S. lydicus (i.e., both have the same inhibition zone distance) but had different growth rates, the fastergrowing isolate would reach the inhibition zone more quickly than the slower-growing isolate (Fig. 2). As a result, the calculated percent growth inhibition for the fast isolate will be greater than that for the slow isolate regardless of the day that the measurements are taken and would lead to the erroneous conclusion that the fast isolate is more sensitive to S. lydicus. However, by the time the slow isolate has approached the same location for the inhibition zone as the fast isolate, additional fungitoxic compounds will have been produced by the $S$. lydicus culture and their continued diffusion into the media will shift the inhibition zone closer to the slow Pythium isolate (determined experimentally to shift approximately $2 \mathrm{~mm} /$ day). This would increase the measured inhibition zone distance and lead to the contradictory erroneous conclusion that the slow isolate was more sensitive to $S$. lydicus because it exhibited a larger inhibition zone than the fast isolate. One final consequence of ignoring the effect of growth rate on inhibitory responses is that this could lead to an incorrect estimation of species and isolate effect sizes. In the present study, analyses without the growth rate covariate indicated that the variation among species $\left(\eta^{2}=0.34\right.$ to 0.48 ) was always greater than that among isolates within species $\left(\eta^{2}=0.23\right.$ to 0.28$)$, regardless of which dependent variable was assessed. However, the analyses that included growth rate as a covariate indicated the opposite for percent growth inhibition at 2 and 7 days (where species $\eta^{2}=0.07$ to 0.08 was less than isolate $\eta^{2}=0.16$ to 0.17 ), and found that the variation among species was similar to that among isolates within species for the inhibition zone analyses $\left(\eta^{2}=0.24\right.$ and 0.23 , respectively). Because individual isolate growth rates affect the outcome of in vitro BCA assays, it is essential to account for differences in growth rate when comparing different pathogen species isolates no matter which measure of BCA inhibition is used. For the purposes of this study, inhibition zone distance was selected as a better measure of BCA inhibition because it was the least affected by growth rate and because it was the most sensitive measure of variability among species, isolates, and locations. However, further studies are needed to determine which measure, percent growth inhibition or inhibition zone distance, is the most accurate predictor of actual BCA efficacy in pathogen-inoculated and BCA-treated plants. As a final note, caution should be observed when assessing inhibition zone distance, particularly with slow-growing isolates. In the hypothetical example presented (Fig. 2), it was not known conclusively until the third day that the slow isolate had stopped growing toward the S. lydicus culture. The distance between the edge of the pathogen isolate and the BCA culture should remain constant for a set period of time ( $24 \mathrm{~h}$ in the present study) to ensure that an accurate inhibition zone distance is recorded.

The results of this study indicate that $S$. lydicus strain WYEC108 is capable of inhibiting all tested isolates of at least 16 Pythium spp. isolated from forest nursery fields, although not equally. The results further provide quantitative evidence that pathogen diversity can influence inhibition by BCAs in vitro, which lays the foundation for more comprehensive greenhouse and field studies involving biocontrol on plants. Whenever possible, initial BCA screening assays should use multiple isolates of each pathogen species to encompass the potential variability within pathogen populations. Consideration should also be given to selecting species and isolates that are representative of the pathogen community or population to which the BCA will be applied. Because of the large effect of pathogen isolate growth rate on growth inhibition, it is recommended that in vitro assays utilize inhibition zone data to measure inhibi- 
tion by a BCA. However, regardless of which measure is used, growth rate must be accounted for when comparing species and isolates with different growth rates. Given the differences in inhibition observed at the community and population level, the greatest potential for observing similar differences in future biocontrol studies will likely occur among different pathogen species and
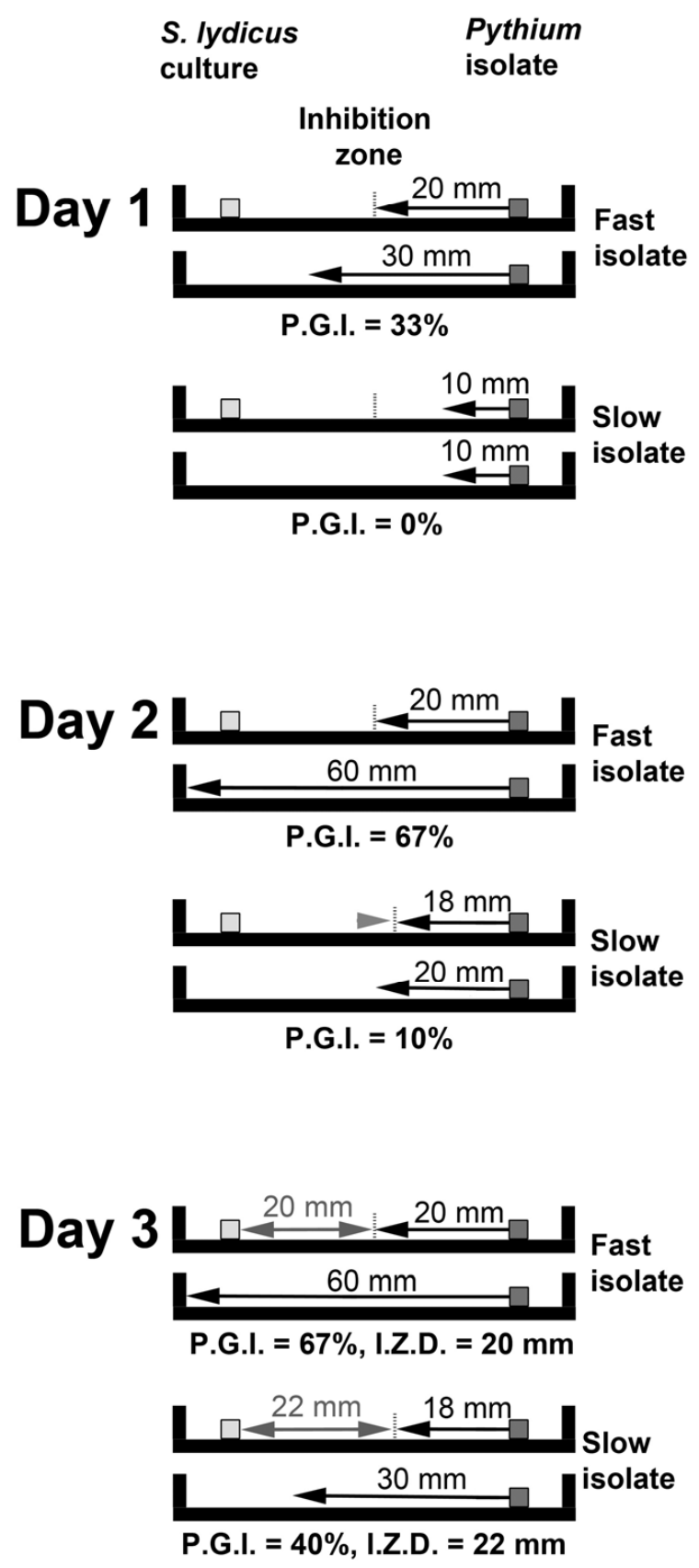

Fig. 2. Diagram illustrating effect of growth rate on percent growth inhibition over 3 days. For each pair of plates with the fast Pythium isolate (growth rate $=30$ $\mathrm{mm} /$ day) or the slow Pythium isolate $(10 \mathrm{~mm} /$ day), the top plate represents the dual-culture plate, with the Streptomyces lydicus culture on the left and the Pythium isolate on the right. The inhibition zone (center vertical bar) for both hypothetical isolates is the same on day 1 , and extends $20 \mathrm{~mm}$ from the $S$. lydicus culture. The lower plate in each pair represents the negative control without a $S$. Iydicus culture. Black arrows represent mycelial growth from the Pythium isolate toward opposite side of plate. By day 2, the inhibition zone for the slow isolate has shifted $2 \mathrm{~mm}$ further from the $S$. lydicus culture (gray arrow) due to the continued production and diffusion of fungitoxic compounds for an additional $24 \mathrm{~h}$. As a consequence, the calculated percent growth inhibition (P.G.I.) is greater and the measured inhibition zone distance (I.Z.D., gray arrows) is smaller for the fast Pythium isolate than for the slow Pythium isolate by day 3. For each day and isolate, P.G.I. is calculated as (1 - growth of Pythium isolate on the dual culture plate/growth of Pythium isolate on negative control plate) $\times 100$. among the least- and most-BCA-sensitive isolates of the same species. Although some evidence was found that pathogen inhibition was influenced by isolate diversity at different locations, the variation among locational responses was comparatively small and it is unknown what significance this will have in the field. Nevertheless, the use of multiple tester isolates of pathogenic species obtained from several locations will help ensure that the results from in vitro assays are more robust. Despite the best attempts of numerous researchers and growers, biological control remains inconsistent in the field. Exploration of factors relating to pathogen diversity prior to field deployment will provide additional insight into the complex relationship between the environment, plant hosts, BCAs, and pathogens which will be necessary for the development of effective biological control strategies.

\section{Acknowledgments}

Financial support was provided, in part, by funds from the United States Department of Agriculture-Agricultural Research Service CRIS Project 535812220-004-00, and grants from the Pacific Area Wide Pest Management Program for Methyl Bromide Alternatives. I thank A. Davis, B. Beck, and D. Kroese for technical assistance; V. Fieland and the Nik Grunwald lab for assistance in the identification of Pythium isolates; and C. Scagel for assistance with statistical analyses.

\section{Literature Cited}

1. Arora, N. K., Kim, M. J., Kang, S. C., and Maheshwari, D. K. 2007. Role of chitinase and beta-1,3-glucanase activities produced by a fluorescent pseudomonad and in vitro inhibition of Phytophthora capsici and Rhizoctonia solani. Can. J. Microbiol. 53:207-212.

2. Campbell, R. 1989. Biological Control of Microbial Plant Pathogens. Cambridge University Press, Cambridge, New York.

3. Crawford, D. L., Lynch, J. M., Whipps, J. M., and Ousley, M. A. 1993. Isolation and characterization of actinomycete antagonists of a fungal root pathogen. Appl. Environ. Microbiol. 59:3899-3905.

4. Cummings, J. A., Miles, C. A., and du Toit, L. J. 2009. Greenhouse evaluation of seed and drench treatments for organic management of soilborne pathogens of spinach. Plant Dis. 93:1281-1292.

5. de Souza, J. T., Arnould, C., Deulvot, C., Lemanceau, P., Gianinazzi-Pearson, V., and Raaijmakers, J. M. 2003. Effect of 2,4-diacetylphloroglucinol on Pythium: cellular responses and variation in sensitivity among propagules and species. Phytopathology 93:966-975.

6. Duffy, B., Schouten, A., and Raaijmakers, J. M. 2003. Pathogen self-defense: mechanisms to counteract microbial antagonism. Annu. Rev. Phytopathol. 41:501-538.

7. Dumroese, R. K., James, R. L., and Wenny, D. L. 1996. Gliocladium virens in an alginate prill ineffective as a biological control of Fusarium root disease in container-grown Douglas-fir. New For. 12:113-124.

8. Dumroese, R. K., James, R. L., and Wenny, D. L. 1998. Interactions among Streptomyces griseoviridis, Fusarium root disease, and Douglas-fir seedlings. New For. 15:181-191.

9. Elliott, M., Shamoun, S. F., Sumampong, G., James, D., Masri, S., and Varga, A. 2009. Evaluation of several commercial biocontrol products on European and North American populations of Phytophthora ramorum. Biocontrol Sci. Technol. 19:1007-1021.

10. Estevez de Jensen, C., Percich, J. A., and Graham, P. H. 2002. Integrated management strategies of bean root rot with Bacillus subtilis and Rhizobium in Minnesota. Field Crops Res. 74:107-115.

11. Frändberg, E., and Schnürer, J. 1998. Antifungal activity of chitinolytic bacteria isolated from airtight stored cereal grain. Can. J. Microbiol. 44:121-127.

12. Fravel, D. 1999. Hurdles and bottlenecks on the road to biocontrol of plant pathogens. Australas. Plant Pathol. 28:53-56.

13. Gracia-Garza, J. A., Little, M., Brown, W., Blom, T. J., Schneider, K., Allen, W., and Potter, J. 2003. Efficacy of various biological control agents and biorationals against Pythium root rot in poinsettia. HortTechnology 13:149153.

14. Guetsky, R., Shtienberg, D., Elad, Y., Fischer, E., and Dinoor, A. 2002. Improving biological control by combining biocontrol agents each with several mechanisms of disease suppression. Phytopathology 92:976-985.

15. Haas, D., and Keel, C. 2003. Regulation of antibiotic production in rootcolonizing Pseudomonas spp. and relevance for biological control of plant disease. Annu. Rev. Phytopathol. 41:117-153.

16. Hansen, E. M., Myrold, D. D., and Hamm, P. B. 1990. Effects of soil fumigation and cover crops on potential pathogens, microbial activity, nitrogen availability, and seedling quality in conifer nurseries. Phytopathology 80:698-704.

17. Hildebrand, D. M., Stone, J. K., James, R. L., and Frankel, S. J. 2004. Alternatives to preplant soil fumigation for Western forest nurseries. U. S. Dep. Agric. For. Serv. Pac. Northwest Res. Stn. Gen. Tech. Rep. PNW-GTR-608.

18. Hoitink, H. A. J., and Boehm, M. J. 1999. Biocontrol within the context of 
soil microbial communities: a substrate-dependent phenomenon. Annu. Rev. Phytopathol. 37:427-446.

19. Howell, C. R. 2002. Cotton seedling preemergence damping-off incited by Rhizopus oryzae and Pythium spp. and its biological control with Trichoderma spp. Phytopathology 92:177-180.

20. James, R. L. 2002. Effects of spring applications of dazomet on root diseases and performance of Douglas-fir and western white pine transplants. United States Department of Agriculture Forest Service Nursery, Coeur d'Alene, ID. Forest Health Prot. Rep. 02-9.

21. James, R. L., Knudsen, G. R., and Morra, M. J. 2004. Preplant soil treatment effects on production of Douglas-fir seedlings at the United States Department of Agriculture Forest Service Nursery, Coeur d'Alene, ID. For. Health Prot. Rep. 04-10.

22. Jayaswal, R. J., Fernandez, M. A., and Schroeder, R. G., III. 1990. Isolation and characterization of a Pseudomonas strain that restricts growth of various phytopathogenic fungi. Appl. Environ. Microbiol. 56:1053-1058.

23. Jones, C. R., and Samac, D. A. 1996. Biological control of fungi causing alfalfa seedling damping-off with a disease-suppressive strain of Streptomyces. Biol. Control 7:196-204.

24. Karimi, E., Sadeghi, A., Dehaji, P. A., Dalvand, Y., Omidvari, M., and Nezhad, M. K. 2012. Biocontrol activity of salt tolerant Streptomyces isolates against phytopathogens causing root rot of sugar beet. Biocontrol Sci. Technol. 22:333-349.

25. Kaushik, J. C., Sanjay, A., and Gupta, P. P. 2002. Management of dampingoff disease in forest nurseries by soil solarization and biocontrol agents. Forage Res. 28:29-31.

26. Kumar, P., Dubey, R. C., and Maheshwari, D. K. 2012. Bacillus strains isolated from rhizosphere showed plant growth promoting and antagonistic activity against phytopathogens. Microbiol. Res. 167:493-499.

27. Leisso, R. S., Miller, P. R., and Burrows, M. E. 2009. The influence of biological and fungicidal seed treatments on chickpea (Cicer arietinum) damping off. Can. J. Plant Pathol. 31:38-46.

28. Linderman, R. G., Masters, C. J., and Davis, E. A. 2008. Efficacy of chemical and biological agents to suppress Fusarium and Pythium damping-off of container-grown Douglas-fir seedlings. Plant Health Progress. Online publication. doi:10.1094/PHP-2008-0317-1002-RS

29. Lorang, J. M., Liu, D., Anderson, N. A., and Schottel, J. L. 1995. Identification of potato scab inducing and suppressive species of Streptomyces. Phytopathology 85:261-268.

30. Mahadevan, B., and Crawford, D. L. 1997. Properties of the chitinase of the antifungal biocontrol agent Streptomyces lydicus WYEC108. Enzyme Microb. Technol. 20:489-493.

31. Mao, W., Lewis, J. A., Hebbar, P. K., and Lumsden, R. D. 1997. Seed treatment with a fungal or a bacterial antagonist for reducing corn damping-off caused by species of Pythium and Fusarium. Plant Dis. 81:450-454.

32. Mazzola, M., Fujimoto, D. K., Thomashow, L. S., and Cook, R. J. 1995. Variation in sensitivity of Gaeumannomyces graminis to antibiotics produced by fluorescent Pseudomonas spp. and effect on biological control of take-all of wheat. Appl. Environ. Microbiol. 61:2554-2559.

33. McGovern, R. J., McSorley, R., and Bell, M. L. 2002. Reduction of landscape pathogens in Florida by soil solarization. Plant Dis. 86:1388-1395.

34. Minaxi, and Saxena, J. 2010. Characterization of Pseudomonas aeruginosa
RM-3 as a potential biocontrol agent. Mycopathologia 170:181-193.

35. Minuto, A., Spadaro, D., Garibaldi, A., and Gullino, M. L. 2006. Control of soilborne pathogens of tomato using a commercial formulation of Streptomyces griseoviridis and solarization. Crop Prot. 25:468-475.

36. Mousseaux, M. R., Dumroese, R. K., James, R. L., Wenny, D. L., and Knudsen, G. R. 1998. Efficacy of Trichoderma harzianum as a biological control of Fusarium oxysporum in container-grown Douglas-fir seedlings. New For. 15:11-21

37. Otto-Hanson, L. K., Grabau, Z., Rosen, C., Salomon, C. E., and Kinkel, L. L. 2013. Pathogen variation and urea influence selection and success of Streptomyces mixtures in biocontrol. Phytopathology 103:34-42.

38. Schouten, A., van den Berg, G., Edel-Hermann, V., Steinberg, C., Gautheron, N., Alabouvette, C., de Vos, C. H., Lemanceau, P., and Raaijmakers, J. M. 2004. Defense responses of Fusarium oxysporum to 2,4-diacetylphloroglucinol, a broad-spectrum antibiotic produced by Pseudomonas fluorescens. Mol. Plant-Microbe Interact. 17:1201-1211.

39. Sokal, R. R., and Rohlf, F. J. 2012. Biometry, Fourth Edition. W. H. Freeman and Company, New York.

40. Tonelli, M. L., Taurian, T., Ibanez, F., Angelini, J., and Fabra, A. 2010 Selection and in vitro characterization of biocontrol agents with potential to protect peanut plants against fungal pathogens. J. Plant Pathol. 92:73-82.

41. Vaartaja, O. 1975. Pythium sylvaticum in Canadian forest nurseries. Can. Plant Dis. Surv. 55:101-102.

42. Verma, V. C., Gond, S. K., Anuj, K., Ashish, M., Kharwar, R. N., and Gange, A. C. 2009. Endophytic actinomycetes from Azadirachta indica A. Juss.: isolation, diversity, and anti-microbial activity. Microb. Ecol. 57:749756.

43. Weiland, J. E. 2011. Influence of isolation method on recovery of Pythium species from forest nursery soils in Oregon and Washington. Plant Dis. 95:547-553.

44. Weiland, J. E., Beck, B. R., and Davis, A. 2013. Pathogenicity and virulence of Pythium species obtained from forest nursery soils on Douglas-fir seedlings. Plant Dis. 97:744-748.

45. Weiland, J. E., Leon, A. L., Edmonds, R. L., Littke, W. R., Browning, J. E. Davis, A., Beck, B. R., Miller, T. W., Cherry, M. L., and Rose, R. 2011. The effects of methyl bromide alternatives on soil and seedling pathogen populations, weeds, and seedling morphology in Oregon and Washington forest nurseries. Can. J. For. Res. 41:1885-1896.

46. Weiland, J. E., Littke, W. R., and Haase, D. L. 2013. Forest nurseries face critical choices with the loss of methyl bromide fumigation. Calif. Agric. 67:153-161.

47. Whipps, J. M., and Lumsden, R. D. 1991. Biological control of Pythium species. Biocontrol Sci. Technol. 1:75-90.

48. Xiao, K., Kinkel, L. L., and Samac, D. A. 2002. Biological control of Phytophthora root rots on alfalfa and soybean with Streptomyces. Biol. Control 23:285-295.

49. Xu, X. M., Jeffries, P., Pautasso, M., and Jeger, M. J. 2011. Combined use of biocontrol agents to manage plant diseases in theory and practice. Phytopathology 101:1024-1031.

50. Yuan, W. M., and Crawford, D. L. 1995. Characterization of Streptomyces lydicus WYEC108 as a potential biocontrol agent against fungal root and seed rots. Appl. Environ. Microbiol. 61:3119-3128. 